\title{
Influence of Periostin on Synoviocytes in Knee Osteoarthritis
}

\author{
YUTARO TAJIKA $^{1}$, TATSUYA MOUE ${ }^{1}$, SHINTARO ISHIKAWA ${ }^{1}$, KAZUHITO ASANO ${ }^{1}$, \\ TAKAYUKI OKUMO $^{1}$, HIROSHI TAKAGI $^{2}$ and TADASHI HISAMITSU ${ }^{1}$ \\ ${ }^{1}$ Department of Physiology, School of Medicine, Showa University, Tokyo, Japan; \\ ${ }^{2}$ Department of Orthopaedic Surgery, Showa University Fujigaoka Hospital, Kanagawa, Japan
}

\begin{abstract}
Background: Periostin (POSTN) is a protein that binds to integrins to support adhesion and migration of epithelial cells. Mice lacking this gene exhibit cardiac valve disease as well as skeletal and dental defects. Recent studies indicated that periostin is involved in the pathogenesis and progression of knee osteoarthritis $(\mathrm{OA})$. We investigated the influence of periostin and matrix metalloproteinases (MMPs) on OA synoviocytes. Materials and Methods: OA patients were classified according to the Kellgren-Lawrence system and the levels of periostin, interleukin (IL)-4, IL-13 and transforming growth factor- $\beta(T G F \beta)$ in the synovial fluid were measured. MMPs or tissue inhibitor of MMPs (TIMPs) with periostin in cultured cells were measured when periostin was added to OA-associated synovial cells. Dexamethasone, a steroid medication which shows immunosuppressive effects, was used to investigate the influence of the downstream cascade. Results: Periostin and IL-13 levels were upregulated during the progression of $O A . M M P-2$ and $M M P$ 3 levels increased in a periostin concentration-dependent manner. Increase in MMP-2 and MMP-3 levels was inhibited by dexamethasone treatment. Conclusion: In vivo results herein indicate that IL-13 may induce periostin production in $O A$. Furthermore, periostin may facilitate MMP production in OA-associated synovial cells.
\end{abstract}

Osteoarthritis (OA) is the most prevalent form of joint disease, where OA symptoms affect $5 \%$ of adults aged over 60 years worldwide (1). It is estimated that $10 \%$ of men and $18 \%$ of women aged over 60 years have symptomatic OA, where $80 \%$

This article is freely accessible online.

Correspondence to: Shintaro Ishikawa, Department of Physiology, School of Medicine, Showa University, 1-5-8 Hatanodai, Shinagawa-ku, Tokyo 142-8555, Japan. Tel: +81 337848110, Fax: +81 337845368, e-mail: s-ishikawa@ med.showa-u.ac.jp

Key Words: Dexamethasone, knee osteoarthritis, matrix metalloproteinase, periostin. experience movement limitations and $25 \%$ are unable to perform normal daily activities (2). The prevalence of OA is rising due to increased life expectancy and risk factors such as obesity (1). It is evident that the inflammatory response is a key contributor to the development and progression of knee OA (3). OA is characterized by articular cartilage damage, low-grade synovial inflammation and hypertrophic bone changes, which lead to functional deterioration (1). Signaling pathways involving growth factors and cytokines are being investigated to facilitate the development of new therapies that target the underlying biological processes causing the disease. This concept of 'molecular orthopaedics' should allow more patient-centred diagnostic and treatment strategies.

The main symptom of OA is pain, which is also the leading factor that makes patients change their lifestyle and seek medical intervention (4). According to the OA Research Society International, the objectives of OA management are to reduce pain and inflammation, slow cartilage degradation, improve function and reduce disability (5). Therefore, important issues in OA treatment is discovering OA's early stage mediator and elucidating the underlying intracellular signal transduction pathway.

Periostin is a member of the fasciclin family of proteins based on its homology with fasciclin I, which was initially identified in insects (6). Periostin, also known as osteoblastspecific factor 2 , is a $93.3-\mathrm{kDa}$ secreted, vitamin K-dependent, glutamate-containing matricellular protein, originally isolated from a mouse osteoblast cell line $(7,8)$. This protein has known functions in osteology, tissue repair, oncology, cardiovascular and respiratory systems and various inflammatory settings. According to recent reports, periostin deposition promotes chronic allergic inflammation by activating nuclear factor kappa B (NF-kB) signaling (9-11). Periostin is considered to be an important structural mediator by balancing appropriate versus inappropriate tissue adaptation in response to insult/injury. Certain studies have shown that periostin is up-regulated in OA tissues (12-14). Previously, we reported that the periostin levels in synovial fluid were upregulated during the progression of $\mathrm{OA}$ in vivo, while in vitro experiments using human fibroblast-like synoviocytes 
suggested that addition of periostin mediated increased matrix metalloproteinase (MMP)-9 production (15). These results indicate that periostin secretion is related to $\mathrm{OA}$ tissue remodelling. However, arthrosis synovia includes chondrocytes and adipocytes as well as fibroblasts. In our previous study, we used fibroblasts so the results did not reflect the reaction of the whole synovial tissue. In addition, the paracrine effect of periostin in OA-synoviocyte biology remains poorly understood.

Therefore, in this study, we re-investigated the production of periostin as well as the cytokines that affect its production in the synovial fluid of the knee in OA patients. Furthermore, we evaluated the influence of periostin on OA-related extracellular matrix modulators $(16,17)$ in synovial tissue cells isolated from the knees of OA patients.

\section{Materials and Methods}

Patients. Synovial fluid was collected from 53 OA patients (mean age, $76.3 \pm 3.9$ years; age range, 68-84 years) who underwent medical examinations at Showa University Fujigaoka Hospital (Yokohama, Japan). The Institutional Review Board at our teaching hospital approved the study protocol (authorization number: 2148) and signed informed consent was obtained from all subjects before their participation in the study. Radiographs were reviewed to determine the size and stage of progression for the OA lesions. Radiographic findings were classified according to the KellgrenLawrence system (18), as follows: grade $1(n=14)$, doubtful joint space narrowing (JSN) and possible osteophytic lipping; grade 2 $(n=15)$, presence of definite osteophytes and possible JSN on anteroposterior weight-bearing radiograph; grade $3(n=11)$, multiple osteophytes, definite JSN, sclerosis, possible bony deformities; and grade $4(n=13)$, large osteophytes, marked JSN, severe sclerosis and definite bony deformities.

Reagents. Periostin (recombinant human periostin/OSF-2, CF) was purchased from R\&D Systems Inc. (Minneapolis, MN, USA) and dissolved in Synoviocyte Growth Medium (M2700-HS; Articular Engineering, Northbrook, IL, USA), which was sterilized by passing through $0.2 \mu \mathrm{m}$ pore filters, and stored at $4^{\circ} \mathrm{C}$ until use. Dexamethasone was purchased from Wako Pure Chemical Ind. Ltd (Osaka, Japan). Dexamethasone was diluted in ethanol in stock solutions at $10 \mathrm{mM}$ according to the instructions of the attached manual and stored in a freezer at $-20^{\circ} \mathrm{C}(19)$.

Synoviocyte culture. Human cryopreserved synoviocytes from an OA donor (CDD-H-2910-OA) were purchased from Articular Engineering (Northbrook, IL, USA). The OA synoviocytes re-suspended at a density of $2 \times 10^{5}$ cells $/ \mathrm{ml}$ in culture medium, before incubated with $0.01,0.1$ and $0.5 \mu \mathrm{g} / \mathrm{ml}$ periostin in combination with/without dexamethasone (final concentration; $100 \mathrm{nM}$ ) in 24-well plates in triplicates. The culture supernatants were collected for cytokines production test after $24 \mathrm{~h}$ and stored at $-80^{\circ} \mathrm{C}$ until use. The cells also were collected to extract the total RNA extraction after $12 \mathrm{~h}$.

Collection of synovial fluid. Synovial fluid was collected from OA patients using an 18-gauge needle and then stored at $-80^{\circ} \mathrm{C}$ until it was assayed.
Assay for biologically-active substances. The periostin levels in synovial fluid were measured using a commercially available enzyme-linked immunosorbent assay (ELISA) kit (catalogue number: EK-074-41; Phoenix Pharmaceuticals, Inc., Burlingame, CA, USA). The concentrations of the inflammatory cytokines, interleukin (IL)-4 and IL-13, and transforming growth factor $\beta 1$ (TGF- $\beta 1$ ) in synovial fluid were measured using commercially available ELISA test kits (catalogue numbers: D4050, D1300B, and DB100B; R\&D Systems, Inc., Minneapolis, MN, USA) according to the manufacturer's instructions. In addition, the concentrations of MMP-1, MMP-2, MMP-3, MMP-13, tissue inhibitor of MMP (TIMP)-1, and TIMP-2 in the culture supernatants were measured using commercially available ELISA test kits (DMP100, MMP200, DMP300, DM1300, DTM100, and DTM200; R\&D Systems, Inc.) according to the manufacturer's instructions. The minimum detectable levels for these ELISA kits were $0.14 \mathrm{ng} / \mathrm{ml}$ for human periostin, $10 \mathrm{pg} / \mathrm{ml}$ for human IL-4, $57.4 \mathrm{pg} / \mathrm{ml}$ for human IL-13, $15.4 \mathrm{pg} / \mathrm{ml}$ for human TGF- $\beta 1,0.006 \mathrm{ng} / \mathrm{ml}$ for human MMP-1, $0.082 \mathrm{ng} / \mathrm{ml}$ for human MMP-2, $0.045 \mathrm{ng} / \mathrm{ml}$ for human MMP-3, $3.1 \mathrm{pg} / \mathrm{ml}$ for human MMP-13, $0.08 \mathrm{ng} / \mathrm{ml}$ for human TIMP-1 and $0.004 \mathrm{ng} / \mathrm{ml}$ for human TIMP-2.

PCR primers and reagent kits. The reagents used for mRNA isolation (TaqMan Gene Expression Cells-to-Ct ${ }^{\mathrm{TM}}$ ) and real-time reverse transcription (RT)-PCR (TaqMan Gene Expression Assays) were purchased from Applied Biosystems (Foster City, CA, USA). These assays were performed according to the manufacturer's instructions (20). To compare the gene expression levels by real-time RT-PCR, we selected MMP2 (TaqMan Gene Expression Assays; Assay ID: Hs01548727_m1) and MMP3 (TaqMan Gene Expression Assays; Assay ID: Hs00968305_m1). 18s, $18 S$ ribosomal RNA (TaqMan Gene Expression Assays; Assay ID: Hs99999901_s1), was used as a housekeeping gene to normalize RNA loading.

mRNA isolation and quantitative RT-PCR. Total RNA was isolated from synovial cells using $50 \mu \mathrm{l}$ of Lysis Solution (P/N4383583). Each total RNA sample was subjected to RT using 20× RT Enzyme Mix (P/N 4383585) and 2x RT Buffer (P/N43833586) with an Applied Biosystems 2720 Thermal Cycler (Applied Biosystems). After the RT reaction, the cDNA templates were amplified by PCR using TaqMan Gene Expression Assays, PCR primers, and RT Master Mix (P/N 4369016). Predesigned and validated gene-specific TaqMan Gene Expression Assays $(16,17)$ obtained from Applied Biosystems were used in duplicate for quantitative RT-PCR according to the manufacturer's protocol. The PCR assays were performed as follows: denaturation for $10 \mathrm{~min}$ at $95^{\circ} \mathrm{C}, 40$ cycles of denaturation at $95^{\circ} \mathrm{C}$ for $15 \mathrm{~s}$, and annealing and extension at $60^{\circ} \mathrm{C}$ for $1 \mathrm{~min}$. Samples were analysed using an ABI Prism 7900HT Fast Real-Time PCR System (Applied Biosystems) (21, 22). Relative quantification (23) was performed using the collected data (threshold cycle numbers, referred to as $\mathrm{Ct}$ ) with an ABI Prism 7900HT Sequence-Detection System (SDS) software 2.3 (Applied Biosystems).

Statistical analysis. The data were expressed as means \pm standard deviations. All of the assays were repeated three times to ensure reproducibility. Significant differences between the control and experimental groups were analysed by one-way analysis of variance followed by the Scheffe test. A probability $(p)$ value $<0.05$ was considered significantly different. 


\section{Results}

Analysis of biologically active substances in synovial fluid. Samples of synovial fluid were analyzed to determine possible correlations between the OA grade and periostin concentration. As shown in Figure 1, the periostin concentration increased significantly with OA progression. Next, we examined the levels of cytokines and TGF- $\beta 1$ in synovial fluid samples. Figure $2 \mathrm{~A}$ shows that the IL-13 levels increased significantly in the samples with the progression of knee OA. As shown in Figure 2B and 2C, there were no significant differences in the IL-4 and TGF$\beta 1$ levels in each stage of OA.

Analysis of biologically-active substances in culture supernatants. Next, we evaluated the association of periostin levels with the OA-related proteins MMP-1, MMP-2, MMP3, MMP-13, TIMP-1 and TIMP-2 in synovial cell. As shown in Figure 3, the MMP-2 and MMP-3 levels increased in a concentration-dependent manner to the periostin levels (Figure $3 \mathrm{~B}$ and $\mathrm{C}$ ). However, there were no significant differences in the MMP-1, MMP-13, TIMP-1 and TIMP-2 levels among groups (Figure $3 \mathrm{~A}$ and D, Figure 4A and $\mathrm{B}$ ). In addition, as shown in Figure 5, the periostin-dependent increase of MMP2 and MMP-3 levels was inhibited by treatment with $100 \mathrm{nM}$ dexamethasone which was adjusted to concentration inhibiting spontaneous production of MMP-2 or -3 (19).

Effects of periostin on the mRNA expression levels of MMP2 and $M M P-3$. Finally, we determined whether the addition of periostin affected the MMP-2 and MMP-3 mRNA expression levels in synovial cells. As shown in Figure 6A and $\mathrm{B}$, periostin significantly increased the mRNA expression levels of MMP-2 and MMP-3 in a dose-dependent manner in the cultured synovial cells. In addition, the periostindependent increases in the MMP-2 and MMP-3 mRNA levels were inhibited by $100 \mathrm{nM}$ dexamethasone (Figure 6C and D).

\section{Discussion}

OA is defined as a disorder where changes in the form and function of joints occur due to regressive changes and hyperplastic changes in the joint constituent tissue. OA is one of the most important reasons for orthopaedic surgery. The characteristic clinical symptoms of knee OA are gradual and progressive pain, joint swelling, and dysfunction, but aching pain is the most common complaint. It is considered that these clinical symptoms may be caused by tissue remodeling, such as degeneration and the loss of joint cartilage caused by ageing or immunological/biochemical changes.

Periostin, originally referred to an osteoblast-specific factor 2, is an ECM protein with a size of $93.3 \mathrm{kDa}(24)$, which belongs to the fasciclin family according to its

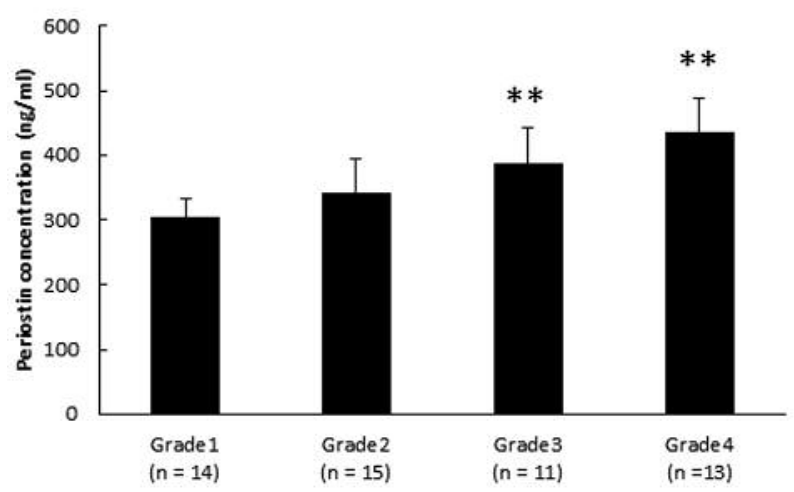

Figure 1. Periostin concentrations in synovial fluid. Correlations between $O A$ grade and periostin levels in synovial fluid: grade $1(n=14)$, doubtful joint space narrowing (JSN) and possible osteophytic lipping; grade $2(n=15)$, the presence of definite osteophytes and possible JSN on anteroposterior weight-bearing radiograph; grade $3(n=11)$, multiple osteophytes, definite JSN, sclerosis, possible bony deformities; and grade $4(n=13)$, large osteophytes, marked JSN, severe sclerosis, and definite bony deformities. Asterisks indicate significant differences $(* * p<0.01 \mathrm{vs.}$ grade 1). Error bars denote \pm standard deviation.

homology with fasciclin 1. Periostin was originally isolated from a mouse osteoblast cell line $(7,8)$ and it has known functions in osteology, tissue repair, oncology, cardiovascular and respiratory systems, and various inflammatory settings. Periostin is characterized as a conventional ECM protein, which is important for the maintenance of organ/tissue structures and for the generation of fibrosis. In addition, periostin is characterized as a matricellular protein, which binds to its receptor, $\alpha v$ integrin, on the cell surface and modulates cell functions (25). For example, intracellular signaling involving periostin appears to enhance osteoblast differentiation and bone formation via $\mathrm{Wnt} / \beta$-catenin signalling (26).

Previously, we reported that periostin (which is considered to play an important role in the induction of tissue remodelling) was up-regulated in the synovial fluid of OA patients during the progression of $\mathrm{OA}$ in vivo. On the other hand, in vitro experiments using human fibroblast-like synoviocytes suggested that periostin may mediate an upregulation in MMP-9 (15). Consequently, periostin may play an important role in the onset and progress of knee OA. Even though, extensive research has helped elucidate the function of periostin, its mode of action in OA remains unknown. Therefore, the aim of the present study was to analyze any effect of periostin in synovial fluid and OA synoviocytes. First, we measured the periostin levels in synovial fluid obtained from the knees of OA patients, which indicated that the periostin levels increased in the synovial fluid with the progression of osteoclasia in OA (Figure 1). In addition, the concentration of the inflammatory cytokine 
IL-13 increased in synovial fluid during the progression of OA (Figure 2A). However, there were no significant differences at the IL- 4 and TGF- $\beta 1$ levels during each stage of OA (Figure 2B and C). IL-4 and IL-13 are immuneregulatory cytokines, which are predominantly secreted by activated Type- 2 helper T (TH2) cells.

Some studies have shown that periostin is a downstream molecule of IL-4 or IL-13, which are highly expressed cytokines in allergic diseases (27). Unlike IL-4, IL-13 does not appear to be important during the initial differentiation of $\mathrm{CD}^{+}$naive $\mathrm{T}$-cells into $\mathrm{TH} 2$ cells because there are no functional IL-13 receptors on human T cells (28-30). Instead, IL-13 is related to the fibrosis of lesion tissue in various types of chronic inflammation because IL-13 receptors are expressed on endothelial cells, fibroblasts and smooth muscle cells. TGF- $\beta 1$ interacts with a number of cartilage extracellular matrix (ECM) proteins and facilitates the regeneration of cartilage. Our results support previous reports that many OA patients harbor gene aberrations in a crucial modulator of TGF- $\beta 1$, asporin (ASPN) (31). The up-regulation of periostin and IL-13 in the synovial fluid of OA patients indicate that they may contribute to the progression of OA.

In addition, in some types of cells, periostin reportedly induces the expression of MMP family members $(13,14)$. This induction and expression of matrix-degrading enzymes may function in tissues containing periostin, which is formed temporarily at the sites of damage to promote remodeling of the original tissue. However, the paracrine effect of periostin as a matricellular protein remains poorly understood in OA of the knee. Our previous in vitro studies of human fibroblast-like synoviocytes suggest that elevated periostin levels mediate increases in the concentration of MMP-9 (15). Several studies have reported increases in the MMP-9 expression levels in knee synovial fluid during the progression of OA $(32,33)$. The present study showed that the capacity of OA-associated synovial cells to produce MMP-2 and MMP-3 was enhanced by periostin stimulation (Figure $3 \mathrm{~A}$ and $\mathrm{B}$ ). However, periostin did not increase the levels of TIMP (Figure 4). MMPs comprise a family of 23 zinc-dependent endopeptidases, which collectively degrade essentially all the components of the extracellular matrix (34). When we looked at knee OA from a biological viewpoint, the breakdown of cartilage matrix and cartilage degeneration caused by chondrocyte apoptosis were found in knee OA. MMP seems to play an essential role in the breakdown of cartilage matrix, where nitric oxide may be involved in chondrocyte apoptosis (35). TIMP is the natural endogenous inhibitor of MMPs and it can inhibit all MMPs in vitro (36). Thus, the relative balance between MMPs and TIMPs is thought to play an essential role in tissue development, morphogenesis, reproduction, and remodeling (37). In this study, periostin did not change TIMP secretion, so MMP/TIMP were dependent on MMP secretion. Furthermore, MMP-3 is a broad-spectrum proteinase with important
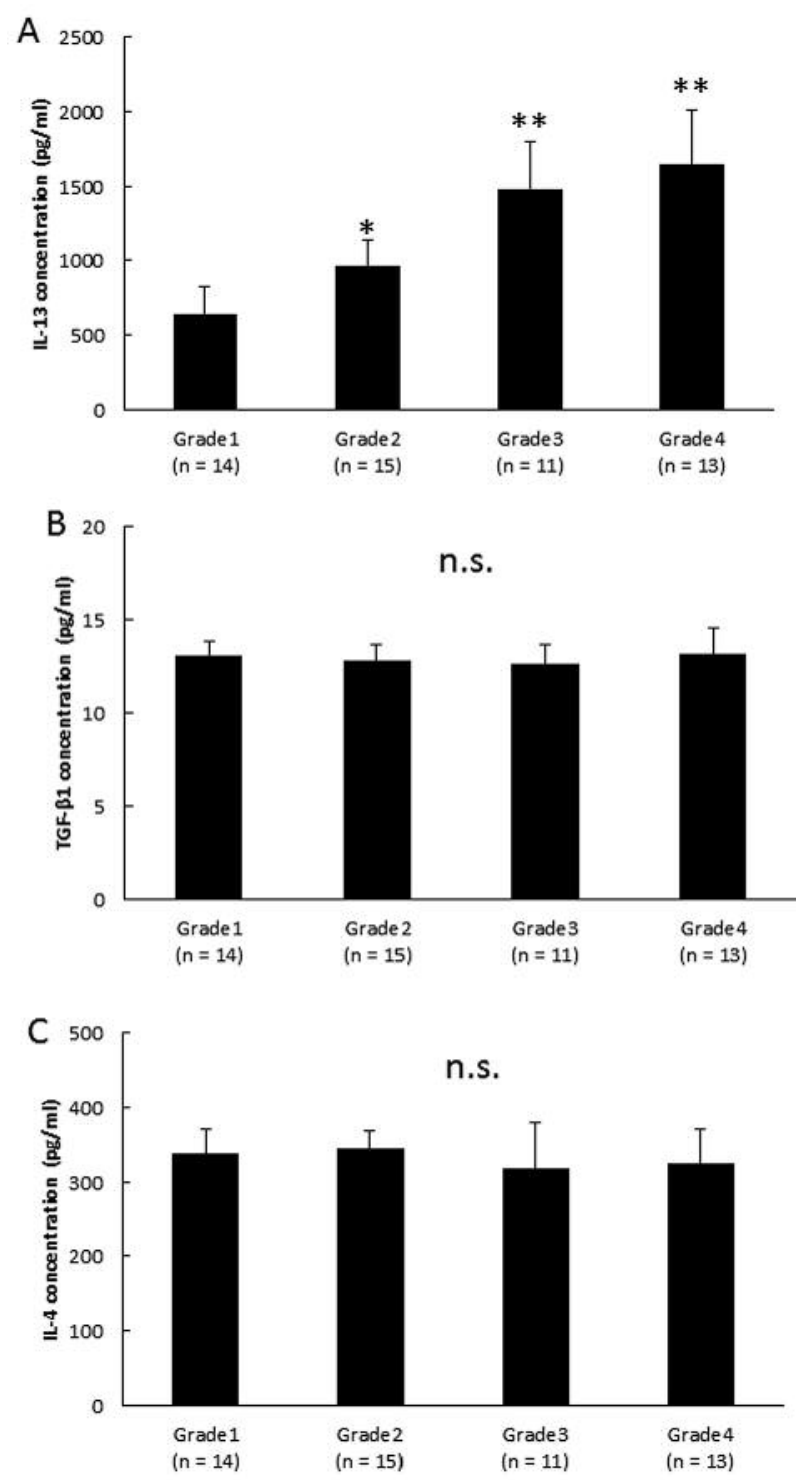

Figure 2. Periostin-related cytokine concentrations in synovial fluid. Cytokines known to promote periostin production in synovial fluid were examined. (A) IL-4 concentrations in synovial fluid. (B) IL-13 concentrations in synovial fluid. (C) TGF- $\beta 1$ concentrations in synovial fluid. Grade $1(n=14)$, doubtful joint space narrowing (JSN) and possible osteophytic lipping; grade $2(n=15)$, presence of definite osteophytes and possible JSN on anteroposterior weight-bearing radiograph; grade $3(n=11)$, multiple osteophytes, definite JSN, sclerosis, possible bony deformities; and grade $4(n=13)$, large osteophytes, marked JSN, severe sclerosis and definite bony deformities. Asterisks indicate significant differences $(* p<0.05 ; * * p<0.01$ vs. grade 1, n.s., no significant difference). Error bars denote \pm standard deviation.

regulatory functions, including the activation of other MMPs (38). Previous studies have consistently detected elevated levels of MMP-3 in the synovial fluid of patients with rotator cuff tears. Gotoh et al. suggested that the endogenous MMP-3 

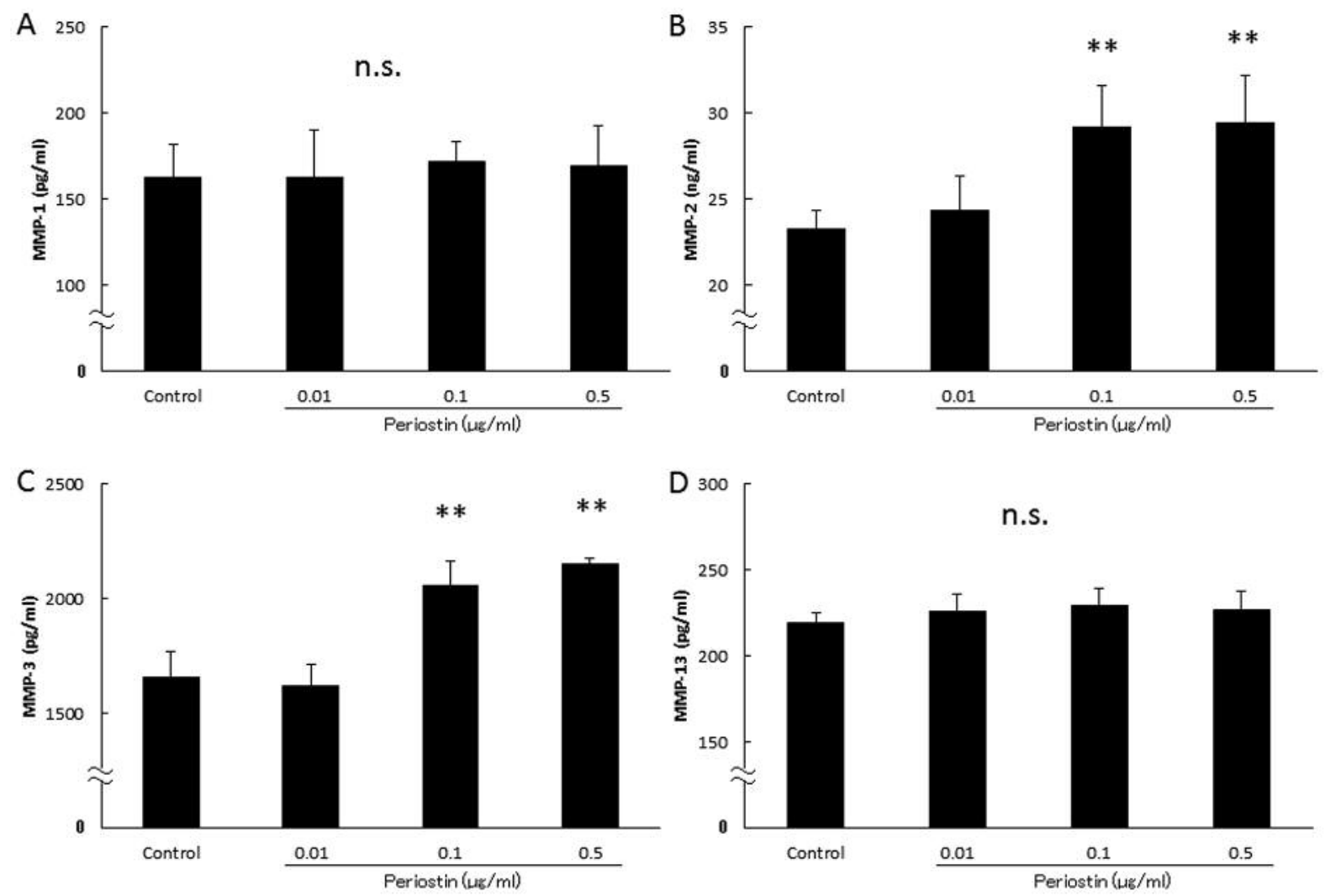

Figure 3. Concentrations of biologically-active substances in culture supernatants. We examined whether addition of periostin changed the MMP2 and MMP-3 production levels in cultured synovial cells. (A) MMP-1 production by cultured synovial cells. MMP-2 production by cultured synovial cells. (B) MMP-3 production by cultured synovial cells. MMP-13 production by cultured synovial cells. (C) TIMP-1 production by cultured synovial cells. (D) TIMP-2 production by cultured synovial cells. Asterisks indicate significant differences $(* * p<0.01$ vs. control, n.s.: no significant difference). Error bars denote \pm standard deviation.
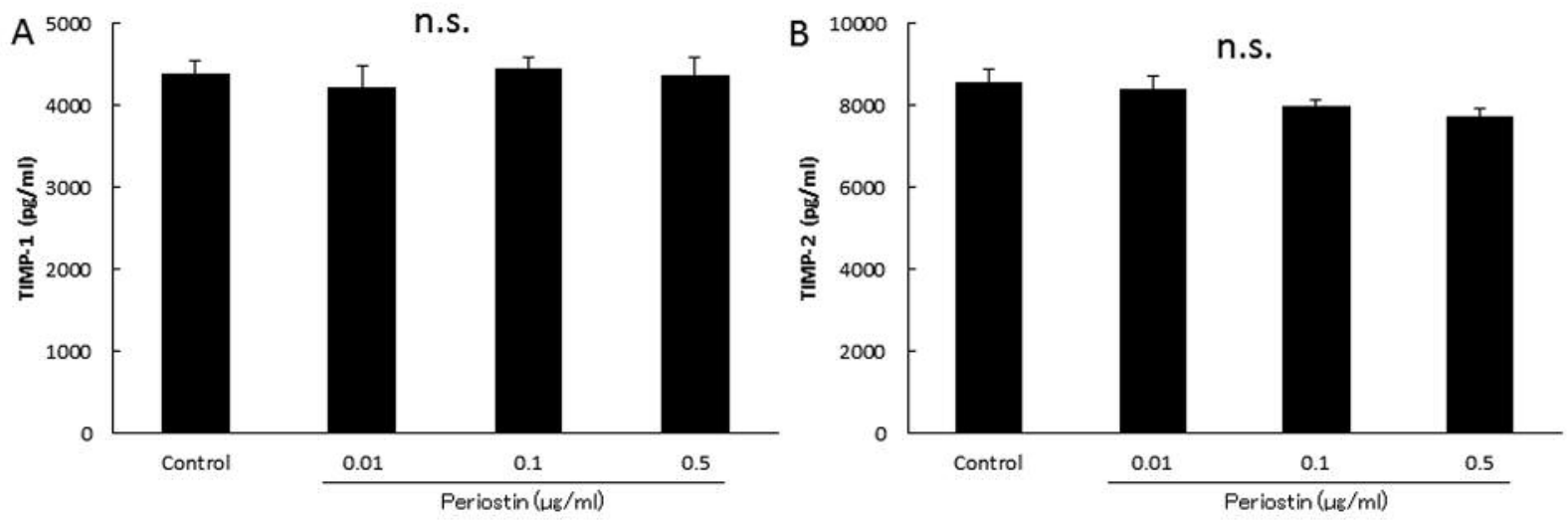

Figure 4. Concentrations of biologically-active substances in culture supernatants. TIMP-1 and TIMP-2 levels in synovial cell cultures following treatment with periostin (A) TIMP-1 production by cultured synovial cells. (B) TIMP-2 production by cultured synovial cells. n.s., No significant difference, error bars denote \pm standard deviation.

activity may have an important role in rotator cuff tears, thereby indicating the possibility of a drug therapy that specifically targets MMP-3 after rotator cuff repair to prevent retearing after surgery (39). Thus, the depression of periostin reaction may inhibit joint destruction by MMPs. Therefore, we examined the levels of MMP in OA when using a pan- 

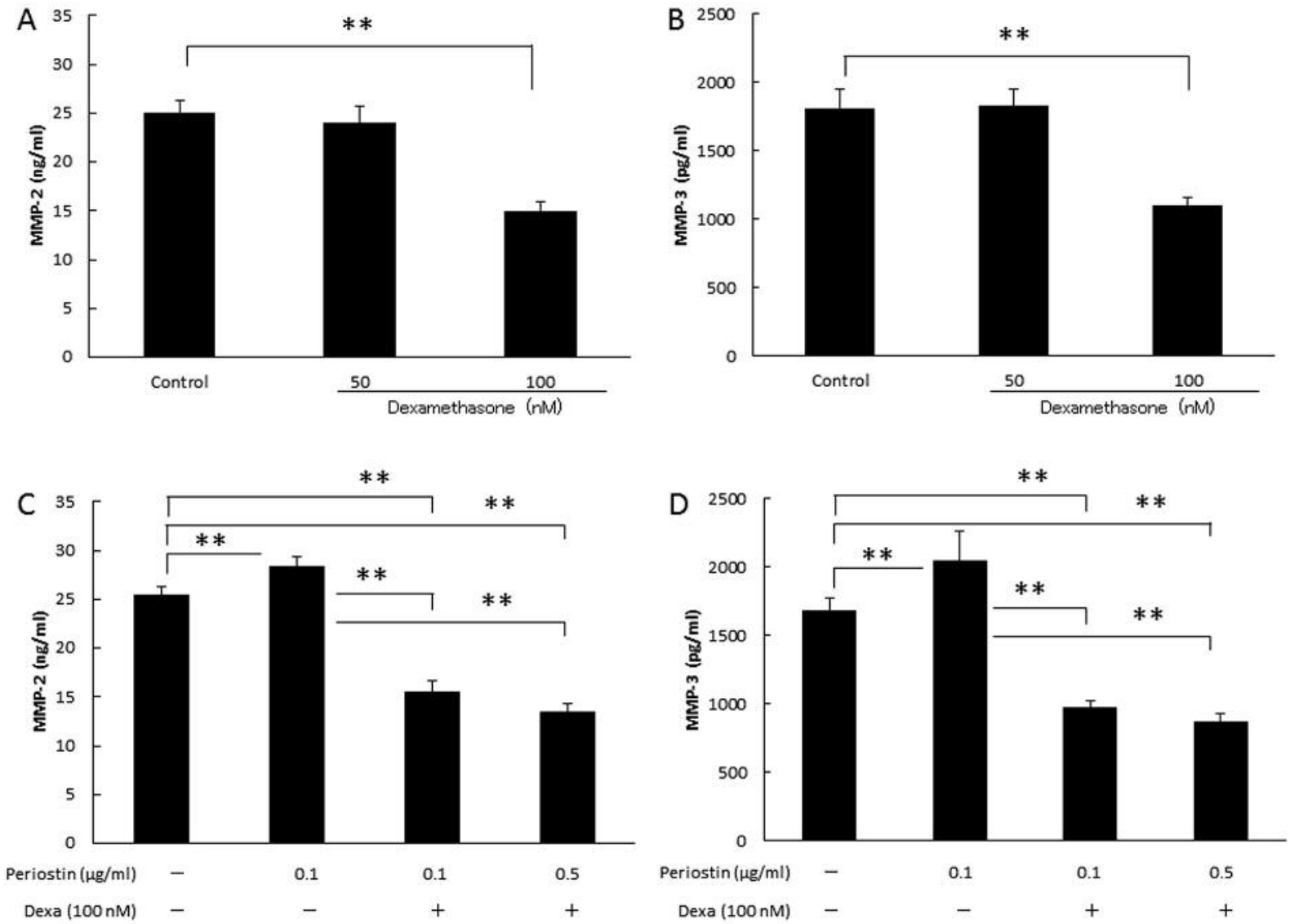

Figure 5. Concentrations of MMP-2 and MMP-3 in culture supernatants with dexamethasone (dexa). Addition of dexamethasone decreased periostatin-mediated MMP-2 and MMP-3 production levels in cultured synovial cells. (A) Effect of the dexamethasone on spontaneous productivity of MMP-2. (B) Effect of the dexamethasone on spontaneous productivity of MMP-3. (C) Suppression efficacy of dexamethasone for periostin's MMP-2 production on synovial cells. (D) Suppression efficacy of dexamethasone for periostin's MMP-3 production on synovial cells. Asterisks indicate significant differences $(* * p<0.01)$. Error bars denote \pm standard deviation.

immunosuppressive agent, dexamethasone, which inhibited the induction of MMP-2 and MMP-3 by periostin in OA synoviocytes (Figure 5). Our results indicate that periostin contributes to the worsening of clinical conditions in OA. Thus, periostin is an important candidate factor that enhances matrix degeneration in chondrocytes via MMP-2 and MMP-3.

Dexamethasone has anti-inflammatory effects and it is possible that its injection into the knee joint of patients with knee OA may inhibit MMP production from joint-derived synovial cells due to periostin stimulation, but it may also damage the cells that make up the joint, as well as regulating the development of joint pain. In our final experiment, we examined the effects of the mRNA expression levels of MMP2 and MMP-3 on OA synoviocytes. Periostin increased the mRNA expression levels of MMP-2 and MMP-3, but they were inhibited by dexamethasone (Figure 6). MMPs play an important role in the ECM because they degrade collagen and proteoglycans in both healthy and diseased patients (40). MMP-3 is viewed as a key regulator of ECM degeneration and remodeling in normal tissue, and Jones et al. claimed that its down-regulation limits MMP activation within tissues (41).

In the context of disease pathogenesis, the expression of MMP and TIMP must be interpreted with respect to the proteolytic consequences of increased MMP/ TIMP ratios (42, 43). Thus, we speculate that the up-regulation of periostin in synovial fluid of the knee in OA may confer a cytoprotective effect to promote tissue repair, and we propose that periostin is a novel biomarker of knee OA progression. Moreover, the intra-articular injection of glucocorticosteroids, such as dexamethasone, is a conventional treatment for OA, but the knees of OA patients injected intra-articularly with steroids sometimes exhibit articular surface destruction, i.e. steroid-induced arthropathy (steroid arthropathy) (44). The principle of steroid-induced arthropathy has not been 

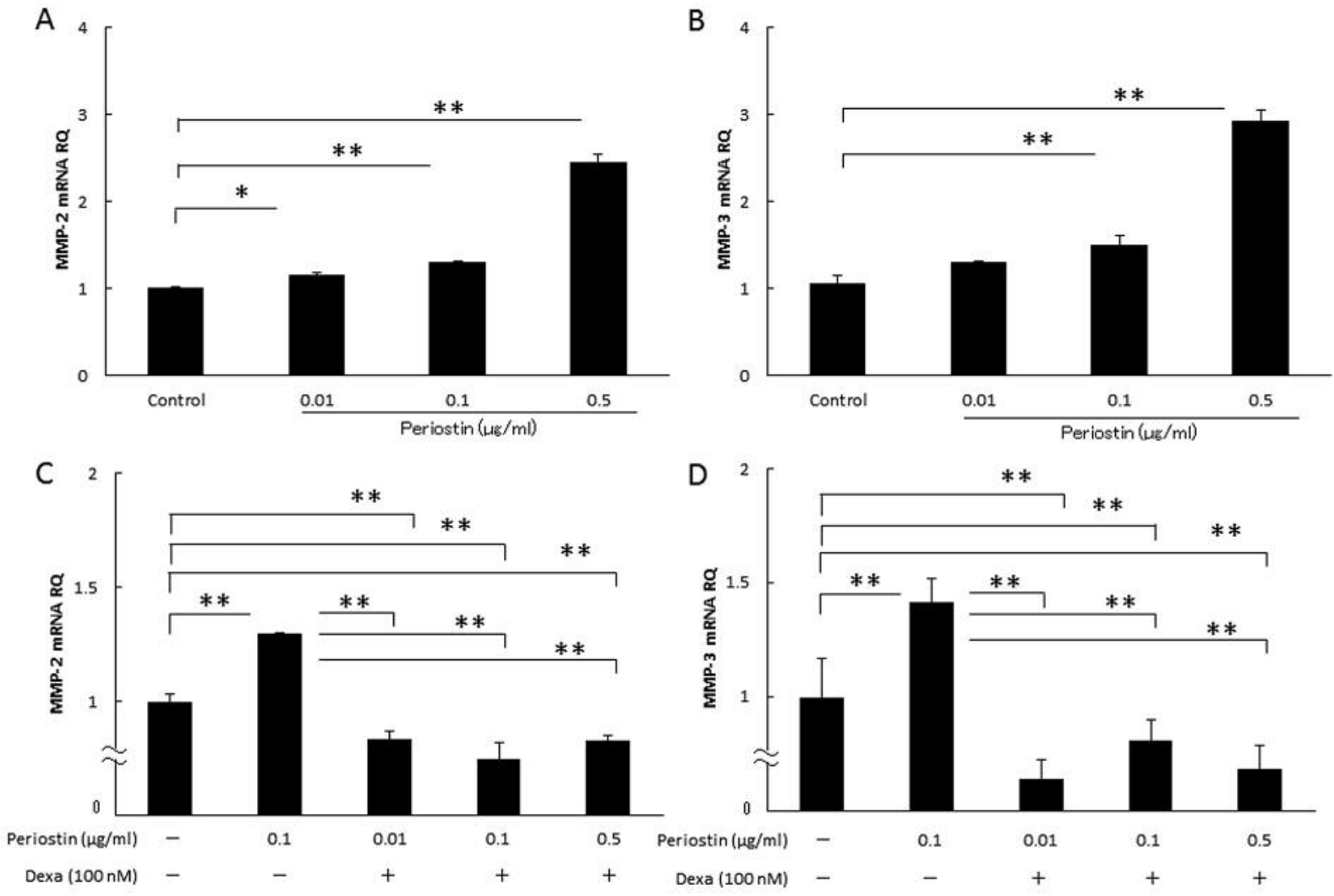

Figure 6. Effect of periostin on the cytokine mRNA expression levels in synovial cells with dexamethasone (dexa). We examined whether the addition of periostin changed the MMP-2 and MMP-3 mRNA expression in cultured synovial cells with dexamethasone. (A) Periostin's MMP-2 mRNA expression by cultured synovial cells. (B) Periostin's MMP-3 mRNA expression by cultured synovial cells. (C) Periostin's MMP-2 mRNA expression by cultured synovial cells with dexamethasone. (D) Periostin's MMP-3 mRNA expression by cultured synovial cells with dexamethasone. Asterisks indicate significant differences $(* p<0.05, * * p<0.01)$. Error bars denote \pm standard deviation.

elucidated in detail, but steroid therapy is very effective as a treatment of acute OA $(44,45,46)$. However, steroid treatment should be used with care in terms of time, niche, and optimum dose. Intra-articular periostin may be employed to determine whether steroid treatment is appropriate. The results of the present study demonstrate that periostin has an important role in the development of OA and our findings suggest that periostin in OA may reflect tissue changes in this chronic degenerative disease. In conclusion, we found that IL-13 and periostin expression is associating with knee OA disease progression. We also inferred that periostin can facilitate MMP production by OA-associated synovial cells and dexamethasone can control the excessive remodeling of joints induced by periostin.

\section{Conflicts of Interest}

The Authors declare that there are no conflicts of interest regarding the publication of this article.

\section{References}

1 World Health Organization (WHO) (2013) Osteoarthritis. Update on background paper 6.12. Available at: http://appswhoint/ medicinedocs/en/m/abstract/Js20259en/ (accessed April 2015)

2 World Health Organization (WHO) (2015) Chronic rheumatic conditions. Available at: http://wwwwhoint/chp/topics/rheumatic/ en/ (accessed April 2015).

3 Wehling P, Moser C and Maixner W: How does surgery compare with advanced intra-articular therapies in knee osteoarthritis: current thoughts. Ther Adv Musculoskelet Dis 8: 72-85, 2016.

4 Hrnack SA and Barber FA: Managing the pain of knee osteoarthritis. Phys Sportsmed 42: 63-70, 2014.

5 Fibel KH, Hillstrom HJ and Halpern BC: State-of-the-Art management of knee osteoarthritis. World J Clin Cases 3: 89$101,2015$.

6 Ohta N, Ishida A, Kurakami K, Suzuki Y, Kakehata S, Ono J, Ikeda $\mathrm{H}$, Okubo $\mathrm{K}$ and Izuhara $\mathrm{K}$ : Expressions and roles of periostin in otolaryngological diseases. Allergol Int 63: 171-180, 2014.

7 Horiuchi K, Amizuka N, Takeshita S, Takamatsu H, Katsuura M, Ozawa H, Toyama Y, Bonewald LF and Kudo A: Identification 
and characterization of a novel protein, periostin, with restricted expression to periosteum and periodontal ligament and increased expression by transforming growth factor beta. J Bone Miner Res 14: 1239-1249, 1999.

8 Takeshita S, Kikuno R, Tezuka K and Amann E: Osteoblastspecific factor 2: cloning of a putative bone adhesion protein with homology with the insect protein fasciclin I. Biochem J 294: 271-278, 1993.

9 Nishiyama T, Kii I, Kashima TG, Kikuchi Y, Ohazama A, Shimazaki M, Fukayama $M$ and Kudo A: Delayed reepithelialization in periostin-deficient mice during cutaneous wound healing. PLoS One 6: e18410. 2011.

10 Masuoka M, Shiraishi H, Ohta S, Suzuki S, Arima K, Aoki S, Toda S, Inagaki N, Kurihara Y, Hayashida S, Takeuchi S, Koike K, Ono J, Noshiro H, Furue M, Conway SJ, Narisawa Y and Izuhara K: Periostin promotes chronic allergic inflammation in response to Th2 cytokines. J Clin Invest 122: 2590-2600, 2012.

11 Taniguchi K, Arima K, Masuoka M, Ohta S, Shiraishi H, Ontsuka K, Suzuki S, Inamitsu M, Yamamoto K, Simmons O, Toda S, Conway SJ, Hamasaki Y and Izuhara K: Periostin controls keratinocyte proliferation and differentiation by interacting with the paracrine IL-1alpha/IL-6 loop. J Invest Dermatol 134: 1295-1304, 2014.

12 Honsawek S, Wilairatana V, Udomsinprasert W, Sinlapavilawan $\mathrm{P}$ and Jirathanathornnukul N: Association of plasma and synovial fluid periostin with radiographic knee osteoarthritis: Crosssectional study. Joint Bone Spine 82: 352-325, 2015

13 Chijimatsu R, Kunugiza Y, Taniyama Y, Nakamura N, Tomita T, Yoshikawa $\mathrm{H}$ : Expression and pathological effects of periostin in human osteoarthritis cartilage. BMC Musculoskelet Disord 16: 215, 2015.

14 Attur M, Yang Q, Shimada K, Tachida Y, Nagase H, Mignatti P, Statman L, Palmer G, Kirsch T, Beier F and Abramson SB: Elevated expression of periostin in human osteoarthritic cartilage and its potential role in matrix degradation via matrix metalloproteinase-13. FASEB J 29: 4107-4121, 2015.

15 Ishikawa S, Asano K, Kusayanagi H, Takashima M, Yoshida N, Yamasaki $\mathrm{E}$ and Hisamiitsu $\mathrm{T}$ : Influence of periostin on synovial fibroblasts in knee osteoarthritis. Chronic Dis Int 2: 1013,2015

16 Muramatsu K, Asano K, Tokita E and Hisamitsu T: Attenuating effect of a COX-2 inhibitor, meloxicam on the production of matrix meeralloproteinases in vivo. Pharma Medica 27: 101-105, 2009. [in Japanese]

17 Fotopoulos VC, Tzinia A, Tzurbakis M, Kalfakakou V, Levidiotou-Stefanou S and Georgoulis A: Expression levels of matrix metalloproteinase (MMP)-9 and its specific inhibitor TIMP-1, in septic and aseptic arthritis of the knee. Knee Surg Sports Traumatol Arthrosc 20: 1159-1167, 2012.

18 Busija L, Bridgett L, Williams SR, Osborne RH, Buchbinder R, March L and Fransen M: Osteoarthritis. Best Pract Res Clin Rheumatol 24: 757-768, 2010.

19 Prota LF, Cebotaru L, Cheng J, Wright J, Vij N, Morales MM and Guggino WB: Dexamethasone regulates CFTR expression in Calu-3 cells with the involvement of chaperones HSP70 and HSP90. PLoS One 7: e47405, 2012.

20 Swartzman E, Shannon M, Lieu P, Chen SM, Mooney C, Wei E, Kuykendall J, Tan R, Settineri T, Egry L and Ruff D: Expanding applications of protein analysis using proximity ligation and qPCR. Methods 50: 23-26, 2010.
21 Barbacioru CC, Wang Y, Canales RD, Sun YA, Keys DN, Chan F, Poulter KA and Samaha RR: Effect of various normalization methods on Applied Biosystems expression array system data. BMC Bioinformatics 7: 533, 2006.

22 Martínez A, Sánchez-Lopez M, Varadé J, Mas A, Martín MC, de Las Heras V, Arroyo R, Mendoza JL, Díaz-Rubio M, FernándezGutiérrez B, de la Concha EG and Urcelay E: Role of the MHC2TA gene in autoimmune diseases. Ann Rheum Dis 66: 325-329, 2007.

23 Kósa JP, Kis A, Bácsi K, Balla B, Nagy Z, Takács I, Speer G and Lakatos P: The protective role of bone morphogenetic protein-8 in the glucocorticoid-induced apoptosis on bone cells. Bone 48: 1052-1057, 2011.

24 Conway SJ, Izuhara K, Kudo Y, Litvin J, Markwald R, Ouyang G, Arron JR, Holweg CT and Kudo A: The role of periostin in tissue remodeling across health and disease. Cell Mol Life Sci 71: 1279-1288, 2014.

25 Izuhara K, Ohta S, Arima K, Suzuki S, Inamitsu M and Yamamoto K: Application of Basic Research to Development of Diagnostics and Therapeutic Agents against lnflammatory Diseases. Rinsho Byori 61: 900-908, 2013. [in Japanese]

26 Kido R and Matsumoto T: Space flight/bedrest immobilization and bone. Signaling cascade induced by mechanical stress. Clin Calcium 22: 1837-1843, 2012. [in Japanese]

27 Takayama G, Arima K, Kanaji T, Toda S, Tanaka H, Shoji S, McKenzie AN, Nagai $H$, Hotokebuchi $T$ and Izuhara $K$ : Periostin: anovel component of subepithelial fibrosis of bronchial asthma downstream of IL-4 and IL-13 signals. J Allergy Clin 1mmunol 118: 98-104, 2006.

28 Hebenstreit D, Wirnsberger G, Horejs-Hoeck J and Duschl A: Signaling mechanisms, interaction partners, and target genes of STAT6. Cytokine Growth Factor Rev 17: 173-188, 2006.

29 Finkelman FD, Hogan SP, Hershey GK, Rothenberg ME and Wills-Karp M: Importance of cytokines in murine allergic airway disease and human asthma. J Immunol 184: 1663-1674, 2010.

30 Ingram JL, Antao-Menezes A, Mangum JB, Lyght O, Lee PJ, Elias JA and Bonner JC: Opposing actions of Stat 1 and Stat6 on IL-13-induced up-regulation of early growth response-1 and platelet-derived growth factor ligands in pulmonary fibroblasts. J Immunol 177: 4141-4148, 2006.

31 Kizawa H, Kou I, Iida A, Sudo A, Miyamoto Y, Fukuda A, Mabuchi A, Kotani A, Kawakami A, Yamamoto S, Uchida A, Nakamura K, Notoya K, Nakamura $Y$ and Ikegawa S: An aspartic acid repeat polymorphism in asporin inhibits chondrogenesis and increases susceptibility to osteoarthritis. Nat Genet 37: 138-144, 2005.

32 Ryu JH, Lee A, Huh MS, Chu J, Kim K, Kim BS, Choi K, Kwon IC, Park JW and Youn I: Measurement of MMP Activity in Synovial Fluid in Cases of Osteoarthritis and Acute Inflammatory Conditions of the Knee Joints Using a Fluorogenic Peptide Probe-Immobilized Diagnostic Kit. Theranostics 2: 198206, 2012.

33 Yang CC, Lin CY, Wang HS and Lyu SR: Matrix metalloproteases and tissue inhibitors of metalloproteinases in medial plica and pannus-like tissue contribute to knee osteoarthritis progression. PLoS One 8: e79662, 2013.

34 Birkedal-Hansen H, Moore WG, Bodden MK, Windsor LJ, Birkedal-Hansen B, DeCarlo A and Engler JA: Matrix metalloprotease: a review. Crit Rev Oral Biol Med 4: 197-250, 1993. 
35 Yamada A, Matsui M and Asano K: Suppressive Activity of Hyaluronic Acid on Periostin-induced Nitric Oxide (NO) Production from Human Synoviocytes in vitro . Jpn Pharmacol Ther 43: 783-789, 2015.

36 Gomez DE, Alonso DF, Yoshiji H and Thorgeirsson UP: Tissue inhibitor of metalloproteases: structure, regulation, and biological functions. Eur J Cell Biol 74: 111-122, 1997.

37 Hellio Le Graverand MP, Eggerer J, Sciore P, Reno C, Vignon E, Otterness I and Hart DA: Matrix metalloprotease-13 expression in rabbit knee joint connective tissues: influence of maturation and response to injury. Matrix Biol 19: 431-441, 2000.

38 Pasternak B and Aspenberg P: Metalloproteinases and their inhibitors-diagnostic and therapeutic opportunities in orthopaedics. Acta Orthop 80: 693-703, 2009.

39 Gotoh M, Mitsui Y, Shibata H, Yamada T, Shirachi I, Nakama $\mathrm{K}$, Okawa $\mathrm{T}$, Higuchi $\mathrm{F}$ and Nagata $\mathrm{K}$ : Increased matrix metalloprotease- 3 gene expression in ruptured rotator cuff tendons is associated with postoperative tendon retear. Knee Surg Sports Traumatol Arthrosc 21: 1807-1812, 2013.

40 Riley G: Tendinopathy-from basic science to treatment. Nat Clin Pract Rheumatol 4: 82-89, 2008.

41 Jones GC, Corps AN, Pennington CJ, Clark IM, Edwards DR, Bradley MM, Hazleman BL and Riley GP: Expression profiling of metalloproteinases and tissue inhibitors of metalloproteinases in normal and degenerate human achilles tendon. Arthritis Rheum 54: 832-842, 2006.

42 Agarwal S, Misra R and Aggarwal A: Synovial fluid RANKL and matrix metalloproteinase levels in enthesitis related arthritis subtype of juvenile idiopathic arthritis. Rheumatol Int 29: $907-$ $911,2009$.
43 Moran EM, Mullan R, McCormick J, Connolly M, Sullivan O, Fitzgerald O, Bresnihan B, Veale DJ and Fearon U: Human rheumatoid arthritis tissue production of IL-17A drives matrix and cartilage degradation: synergy with tumour necrosis factoralpha, Oncostatin $\mathrm{M}$ and response to biologic therapies. Arthritis Res Ther 11: 113, 2009.

44 Schumacher HR and Chen LX: Injectable corticosteroids in treatment of arthritis of the knee. Am J Med 118: 1208-1214, 2005.

45 Heard BJ, Barton KI, Chung M, Achari Y, Shrive NG, Frank CB and Hart DA: Single intra-articular dexamethasone injection immediately post-surgery in a rabbit model mitigates early inflammatory responses and post-traumatic osteoarthritis-like alterations. J Orthop Res 33: 1826-1834, 2015.

46 Bellamy N, Campbell J, Robinson V, Gee T, Bourne R and Wells G: Intraarticular corticosteroid for treatment of osteoarthritis of the knee. Cochrane Database Syst Rev 2: CD005328, 2006.
Received November 4, 2016

Revised November 18, 2016

Accepted December 19, 2016 